\title{
CONSIDERATIONS ABOUT THE PERMANENCE OF THE SUGGESTION IN THE CONTEXT OF TRANSFER: AN INTRODUCTORY STUDY IN THE FREUDIAN TEXT
}

Luciana Bacellar Leal Ferreira and Nadja Nara Barbosa Pinheiro

Luciana Bacellar Leal
Ferreira
Universidade
Federal do
Paraná (UFPR),
Departamento
de Psicologia,
Curitiba/PR, Brasil.
Nadja Nara Barbosa
Pinheiro
Universidade
Federal do
Paraná (UFPR),
Departamento
de Psicologia,
Curitiba/PR, Brasil.

ABSTRACT: The article is based on the hypothesis that suggestion - abandoned as a technique since the beginning of psychoanalysis - once understood as a process inherent of psychic functioning, remains active in transference. It relates suggestion, symptom and dream in order to show that, since the beginning of Freud's work, the permanence of suggestion in transference is linked to something that escapes the analyst's control. Freud's papers, from his first publications to Dora, are analyzed.

Keywords: Suggestion, Psychoanalysis, Symptom, Dream, Transference.

RESUMO: Considerações sobre a perenidade da sugestão no âmbito da transferência: um estudo introdutório no texto freudiano. $\mathrm{O}$ artigo apoia-senahipótese de que a sugestão — abandonada como técnica nos primórdios da psicanálise — uma vez compreendida como processo inerente ao funcionamento psíquico permanece atuante na transferência. Relaciona sugestão, sintoma e sonho visando evidenciar que, já no início da obra freudiana, a perenidade da sugestão no âmbito da transferência encontra-se associada ao que desta última escapa ao controle do analista. Para tal, percorre textos que vão das primeiras publicações à Dora.

Palavras-chave: Sugestão, psicanálise, sintoma, sonho, transferência.

DOI - http://dx.doi.org/10.1590/S1516-14982016002005 


\section{INTRODUCTION}

The assertion that the psychoanalytic clinic has its starting point from the time when Freud abandoned the deliberate use of suggestion does not seem to be, at first, a reason of strangeness. In sequence, the idea that from this abandonment the transference phenomenon emerges as a clinical operator par excellence of psychoanalysis, it also appears to us as a statement free of major controversy. Without any intention to make a retraction of this theoretical systematization, we would like to problematize it. Not aiming to undo it in terms of a possible articulation, but rather to consider that there is something of the suggestion that escapes the control of the analyst and that, on the basis of the transfer itself cradle of the psychoanalytic plot - will remain operative in the clinical process.

At first, it seemed interesting to start this paper with a precise definition of what we understand here as suggestion - beyond its delimitation as a technical resource. That definition, as we will try to demonstrate, is fully apprehensible from the Freudian text, from his early writings, yet not systematized. Because it is alessobviousmodeofthinking aboutthesuggestivephenomenonand because we believe that the scope of this concept of suggestion already involves in itself relevant clinical consequences, we will start from a simplified version of this definition so that, throughout our reflections, we can add the various tones of the suggestion that will allow us to say that it is something that stands on the horizon of the psychoanalytic clinic irrespective of its formal abandonment as a technical resource.

As an initial definition of the suggestive phenomenon, we propose to understand it as an intrinsic process to the psychic functioning, from which the analysant is always subject to make attributions to his analyst - attributions relating to what he supposes the analyst expects, attributions to the analyst's personal characteristics, attributions relating to what the analyst meant in a specific sentence, on a certain situation. With more or less sharp outlines, this tendency to attribute will be here approached as something that, from the suggestive phenomenon, survives despite Freud's decision to no longer suggest.

In relation to transfer, this is a concept that originated an immeasurable theoretical production, which does not exhaust the need for reflections on the subject. The great intimacy of the psychoanalyst with the concept does not avoid the difficulties imposed to the management of the phenomenon within an analytical process. The statement that there will always be an uncontrollable aspect in the transfer is the clinical resultant of our hypothesis; the uncontrollable one which will credit to the suggestion itself. So it seems justifiable to return to the Freudian text to highlight the genuine way the author conceives the relationship between these two elements - suggestion and transfer - and what the consequences originated here to the clinical management are. 
The central idea around which our hypothesis is organized is the observation that, at the beginning of his work, Freud subverts the way that suggestion was understood at that time. The notion that suggestion was an effect of an experienced outside influence as if it emerged spontaneously does not lose, for Freud, its consistency in terms of an experience that was lived psychically. However the author problematizes this sequence with a questioning about what exactly occurs for this to happen.

The answers that Freud offers to this interrogation forward us to something previous than the power of the medical authority - in this case, the hypnotist. And it is in this direction that we will try to write our paper. We stress that what comes before here does not refer to a chronological precedence, but is part of a logical requirement: an assumption that justifies the way by which suggestion works. Relying on Freud's transfer concept, without losing sight of the focus on suggestion, we believe it's possible to find what assumption deals with this issue.

Although it is not our goal to detail the factors that led Freud to break up the technique of suggestion from his practice, we cannot fail to point out his displeasure about the obscurities of the processes involved in the hypnotic suggestion: "I blame this technique for hiding from us the game of psychic forces". (FREUD, 1905/1900, p. 245). The non-treatment of resistances was for him the reason why the symptom returned or just changed.

However we believe it is interesting to highlight some peculiarities concerning Freud's interest in the clinical work of Jean Martin Charcot and that of Hippolyte Bernheim, aiming to underline a concept of suggestion that will allow us to support our hypothesis.

In the preface to the Brazilian Edition of Ola Andersson's book, entitled Freud before Freud, the author of the preface and also the book translator, Luiz Carlos Uchôa Junqueira Fo, mentions Freud's enchantment before Charcot's irrefutable freedom, especially if compared to his Viennese master, Meynert, constantly obsessed by the idea of the anatomical location of disturbances. (ANDERSSON, 2000).

As to Bernheim - and his opening to the marginal practice of hypnosis we have, according to Alfred Lorenzer, "the expression of a progressive posture of readiness to emancipate from the dominant prejudices" (LORENZER, 1987, p. 75) which Freud regarded with profound admiration. We will try to emphasize not only the context in which Freud elaborated his early theories about the phenomenon of suggestion, but also how much it was already possible to conclude from his first reflections a rather individual point of view in relation to the place of suggestion in the doctor-patient relationship.

Later we will analyze the Freudian texts in which the question of transfer begins to stand out in a more explicit way. From his studies on hysteria and his 
investigations into the dreams, to the reflections from the analysis of Dora, we will pursue along this path to highlight the aspects that, we believe, support our proposition on the permanence of suggestion in the context of a clinic in which the transfer is already clearly outlined.

\section{THE LEGACY OF CHARCOT AND BERNHEIM}

We will start, then, by the Freudian translation of Charcot's lectures. Freud makes a reflection that hasn't lost its up-to-dateness. He points out that one of the merits of these conferences is the singular way Charcot used to deal with the diagnosis issue. When he was introduced for the first time to a patient, Charcot, just like "all of us" (FREUD, 1892-4/1990 p. 198), established comparisons between what was before him, a set of symptoms, with his doctor expertise as a result of his professional experience. This first step was nothing of a surprise. It was the current diagnostic logic that we've decided not to place as a logic that is overcome nowadays: the visible and detectable signs in the alleged case, framed in accordance with the doctor's clinical file.

Charcot's originality, in Freud's opinion, consisted in what he was able to perform, once clarified the grounds on which he had based his identification. According to him, Charcot kept the clinical case as a base, as a kind of backdrop, but returned his attention to the peculiarities of the case, to the aspects that did not fit a full framework. Freud refers to these aspects as details that are often deleted, and yet, in a careful observation, be grouped in one or more series that, away from such original frame, no longer seems viable to take them only in accordance to the formal diagnosis. For Freud, Charcot invites us to go on investigating the rudimentary clinical forms, undetermined.

The suggestion, as it will be forwarded along with this article, will be placed more on the side of analysant than that of the analyst, that is, one has to think about suggestion also as something that leads us inexorably to the peculiarities of each clinical case. And this way of approaching the suggestive phenomenon, which we believe is present in Freud from the beginning to the end of his work, will only show to be coherent - at least in terms of clinical guidance - if it's understood in accordance to Charcot's diagnostic proposal. What we intend to keep as our objective until the end of this paper, exploring the early stages of the Freudian work, is that the suggestion as a psychic modality obliges us, from the analyst's position, to move along such rudimentary and uncertain spaces as the ones marked by Freud in reference to Charcot's diagnostic method.

ForCharcottheinadequacy of hysteria to the conventional anatomical-clinical method was not a reason to consider it anything else but a disease (ANDERSSON, 2000). One ratifies that from his work, hysteria broke free of the perjury of the 
simulation and acquired a status of a nervous illness: neurosis. It was literally on Charcot's stage that the theater of hysteria legitimized the hysterical suffering: the hysterical scene turns out to incorporate the truth of the symptom.

We believe it is important at this point to resume the controversy between Bernheim and Charcot. This controversy that marked a quite evident clinical distinction between the schools: Nancy and Salpetriere, respectively. While for Charcot the hypnoid states were strictly pathological and kept the status of a nervous disease to hysteria, for Bernheim hypnosis was nothing but an effect of suggestion. Therefore, the same effects could also be achieved by the suggestion in the waking state. It is important to point out that Bernheim disputes Charcot using hypnosis, but preserves the operating place of suggestion in the treatment, more specifically in the suppression of the symptom. And this is the specific turning point from which Freud will follow his own path in moving into unprecedented grounds (ibdem).

This unique path of Freud will circumscribe suggestion under the psychic context in a quite original way. The option for its abandonment under the condition of therapeutic technique, or even as a tool for the elimination of symptoms does not match the absence of questionings by Freud about the mysteries that were still orbiting around the phenomenon of suggestion. A guidance given by Charcot, in which he warns of the dangers triggered by the use of suggestion and for this reason recommending absolute caution, leads Freud to reflect intensely about this theme (FREUD, 1905b).

Bernheim, as much as Charcot, did not escape the trend of his time: the knowledgeaboutthediseaseabsolutelyestablishedundertheaegis ofthemedical authority (LORENZER, 1987). Although caused by more therapeutic interests, and somewhat less pretentious in terms of statements and evidence than Charcot, Bernheim gave up hypnosis, but did not give up the place occupied by the hypnotist. When he proposed a therapeutic process favoring the word, he kept the direction by the effect of the medical authority. The talks would be, first of all, guaranteed by this authority: the patient refuses hypnosis to reach the source of his pathology because the medical authority is enough to make him go on.

The comments we've just examined, transmit the relevance of the works of Charcot and Bernheim for the beginnings of Freud's elaborations. From Charcot, Freud inherits a conception of hysteria free from the perjuries of the simulation, the legitimation par excellence of its object of study. From Bernheim, nothing less than the importance of the word. Lucky inheritance that, regardless any subsequent divergence, will assist Freud until the end of his work.

We emphasize that our purpose here is not to contextualize the presented facts historically, but circumscribe in which specific points Freud, despite his enchantment, will assume an irreversible distance of their masters. And, espe- 
cially, how many of these same points will be essential to follow the idea that we will try to develop within the general framework of this paper: the fact that suggestion remains in the transference relationship, but no more on the side of the analyst. As a psychic functioning modality, inscribed on the side of analysant. To carry out our purpose we will resume some aspects related to suggestion raised earlier. Our goal now is to highlight what, in Freud's observations about the suggestive phenomenon, would allow us to say that even before the systematization of the concept of transference love, it is possible to deduce the way Freud will be gradually broadening the notion of suggestion for something that encompasses much more than a guideline from the doctor (external). We believe - and that's what we will try to show - that Freud extends the notion of suggestion in order to undermine the logic that something in this phenomenon works from the outside in. When we follow his footsteps, it is significantly evident of how much, for him, suggestion is real just because, on the basis of a psychic process (internal), it (the suggestion) can be experienced as from outside. Also, we will bring other passages that are forwarded to us for the understanding of suggestion as an inherent mechanism to the psychic in general, no longer restricted to the field of pathology.

\section{SUGGESTION AND PSYCHE IN THE EARLY WRITINGS OF FREUDIAN}

In the preface to the translation of Bernheim's book, De La Suggestion — Freud (1888b/1990) presents a very personal association between the phenomenon of suggestionand psychicdynamics.Bernheimwasinterestedinsuggestion because hetookitasagenericcause of hypnoticstates. Theimportance of suggestioncame from what it was able to cause, of its therapeutic efficiency. Contrary to what we will see in Freud, Bernheim did not appear to be so impacted by the possibility that, in this process, the hypnotized were also functional in economic terms. Although with no major concerns about what makes someone suggestionable in terms of a psychic dynamics, his belief that suggestion would be the origin of hypnotism was already a definition in itself:

"All the phenomena of hypnotism have the same origin: that is, they arise from a suggestion, from a conscious idea, which was introduced by an outside influence, in the brain of the hypnotized person and it was accepted as if it had arisen spontaneously. In this respect, all the hypnotic manifestations would be psychic phenomena, effects of suggestion" (FREUD, 1888b/1990, p.126).

This notion of "conscious idea", the "external influence" that — in the words of Freud to introduce Bernheim — was "accepted as if it had arisen spontane- 
ously", does not lose its consistency on the path that will follow Freud in the future. But, one has to recognize how much this supposed acceptance will not remain, in Freud, treated with such simplicity: what exactly can be accepted when you are the target of suggestion? If there is an "outside influence" and an idea "accepted as if it had arisen spontaneously" what turns them into a gear that works in order to modify a symptom? This is the problematic that, we believe, Freud introduces by bringing suggestion in all its complexity to the field of psychological mechanisms. And whose answers, it seems, refer us to the field of transferential relationship.

For Freud, the specificity of Bernheim's book consists in the support of the hypnotic phenomena in a sole conjunction from the fluent processes of the waking life and also of the sleep, removing it from the disbelief and rejection condition that it was attached. "With this, the issue of hypnosis is entirely transposed to the sphere of psychology, and 'suggestion' is built as the core of hypnotism and a key to understand it" (ibdem, p. 123)

In the scope of our hypothesis, and mainly in an attempt to demonstrate how much suggestion is still, to some extent, activating the analytical work, we also highlight Freud's following remark in this text:

"In the second part of the book, there are convincing evidences that the use of hypnotic suggestion gives the doctor a powerful therapeutic method, which actually seems to be best suited to combat certain nervous disorders and the most appropriate to the mechanism of the same" (ibdem, p. 123).

What most interests us in the quotation above is Freud's ratification that something on hypnotic suggestion acts in accordance with the way the mechanism of nervous disorders functions. The clinical method echoes in so far, on the other side, to a certain way of psychic organization which turns out to be compatible to something that, we can say, would be the driving force of this method.

We note that this conception of suggestive effect as consequence, related to a particularity of the psyche, can be once again inferred when, while defending the safety of hypnosis - since applied with proper care and in carefully selected cases - Freud declares:

\footnotetext{
"It should be added that little is gained by calling suggestions as 'obsessive ideas' and hypnosis as 'experimental psychosis'. It seems likely that obsessive ideas will be better clarified if compared to those suggestions, instead of the other way around “(ibdem, p. 125).
} 
Therefore, it seems plausible to say that Freud is, at this moment, taking suggestion as a tool to assist in the understanding of a circuit of symptomatic training (obsessive ideas). More than that, it seems plausible to assert that suggestion, here, is not limited to what comes as the doctor's guidance.

The approach of the suggestion with the neurotic symptom puts it mandatorily on the patient's side: what, in the words of the hypnotist, is experienced, is lived, as suggestion, only happens because the patient has the ability to receive it as such: the suggestibility of the hypnotized, if not precedent, is at least concomitant to the suggestion of the hypnotist. This reversal — that nowadays no longer configures as a logic novelty - brings a clinical consequence of extreme significance, whose relevance is still updated.

Up to this point we've tried to demonstrate how suggestion was, from the beginning, understood by Freud in interdependence with the psyche. And that the suggestive effect only happens because the psychic functioning (here still restricted to the pathological field) allows it. We know that such relationship, in this moment, still appears to be stumbling. Our purpose until this moment has not been to detail how Freud will treat this connection, but to point out that, from the beginning, he already gave indications that to understand what was going on in the treatment of hysteria, something more than the simplistic version of the submission to the medical authority would be needed. Respect and trust in the doctor were enough only in the condition of perquisites for the process to happen - under hypnosis or not. But, by themselves, they did not justify the fact that concrete changes could occur, that the symptoms could be wiped out or displaced. The assertion that suggestion would be responsible for the clinical deeds - were those by Charcot or Bernheim — didn't respond to the fact that it (the suggestion) did "something", even if they were sometimes temporary. Freud changed what could be an answer — so everything originates from suggestion - into a questioning: how does suggestion work? What makes someone suggestible?

Our expectation, to this point, is that we could have been able to pass with proper clarity how subversive Freud was being in relation to his own principles when he reverses the sequence agreed by the critics of hypnosis and proposes that suggestion has more to tell us about the mechanism of the symptoms ("obsessive ideas") than the opposite.

\section{THE ANTICIPATION OF TRANSFERENCE-LOVE: THE STUDIES}

\section{ON HYSTERIA TO DORA}

In Hysteria, Freud describes a hysterical event characterized by the possibility of "transferring an anesthesia, a paralysis, a contracture, a tremor, etc. to the sym- 
metric area the other half of the body ('transfert'), while the originally affected area is normalized" (FREUD, 1888a/1990, pp. 94 and 95). That same year, in the preface to the translation of Bernheim's De La Suggestion, earlier quoted, he resumes the subject and says that the hysterical transfert, whether spontaneously or by suggestion, points to the important fact that the hysterical phenomena are "ruled by laws" (FREUD, 1888b/1990, p. 127). Transference ("transfert") is here a synonym of displacement. However, the confirmation that this event may be repeated through suggestion, that is - in the case of a medical order - brings in the idea that this is an updatable phenomenon through the desire of someone whom the patient assigns some authority.

In order to not move away from the essence of suggestion, we believe to be relevant to point out that the description of the hysterical transfert, in dynamic terms, is the very definition of hysteria that Freud had introduced in Hysteria (1888a/1990), namely: that hysteria is an excess of excitement in the nervous system, able to move with great mobility along its parts (of the nervous system) but always restricted to it. More than a displacement of excitabilities of the nervous system that explains the pathology, we have in this same displacement, a mechanism which coincides, becomes identical, the hysterical pathology itself. For now, we want to draw attention to the possibility of inferring that, here, we have in the principles of excitability displacement that organize hysteria, the same principles that will explain the affection displacement from the perspective of the transference phenomenon. The mobility of excitations that caused the hysterical symptom - and in the case of the hysterical transfert, possible because of suggestion-doesn't differ in structural terms from the mobility of affections (excitations) which will enable the emergence of the transference. As well as a paralyzed arm is not conceived in exteriority to psyche, the place, always singular, conferred to the analyst in the transference relationship, will not be as well.

In The Psychotherapy of Hysteria (FREUD, 1895/1990), having abandoned hypnosis, Freud used the technique of suggestion, supported by the imposition of the hand on the patient's forehead. The goal now was that the patient spoke, from his symptoms, everything that occurred to him. Very well marked by Chertok and Stengers, "it wasn't the hypnosis as an instrument of suggestion, but as an instrument of research and recollection that should be reinterpreted" (CHERTOK and STENGERS, 1990, p. 61)

In this sense, it was already attributed to the doctor-patient connection its valuable appreciation as an enabler of the treatment. Freud relates some cases in which the personal relationship with him temporarily developed brighter colors than the original reason why the patient looked for him. However, according to him, this was an indispensable procedure so people could get the necessary 
confidence. Later, he continues: "there is an emotional factor, the doctor's personal influence, which we can rarely dismiss, and in many cases, just this last factor is able to eliminate the resistance (ibdem, p. 276).

In this article the term transference was used for the first time in the meaning adopted by psychoanalysis in general. Freud establishes three situation s in which a disturbance in the doctor-patient relationship would work as an obstacle to the progress of the analysis process (ibdem, pp. 290-292). The first situation would be if there is a personal feud, i.e. the patient feels disregarded by the doctor or he says he has heard unfavorable criticism to him or to the method of treatment itself. The second type of situation is the one in which the analysant is afraid of becoming dependent, in personal terms - even sexually-on the figure of the doctor. What for Freud could be justified by the context of the treatment itself in which the attention and the care provided by the doctor would be decisive, much more than his personal attributes. And finally, there is the third type, in which, according to Freud, the patient develops a false connection with the doctor, that is, he shifts to himself affection representations previously banished from his consciousness. The analyst becomes therefore a kind of reincarnation of the forbidden desire. Only the latter case of resistance is approached by Freud as a transference product. The first two, though referred to the person of the analyst, are not treated as such by him.

However, we could, with the first, ask ourselves what other phenomenon, if not the transference, could be behind the feeling of disaffection experienced by the patient. Even considering the overdetermination of the psychic events, in our opinion, this complaint addressed to the analyst is only possible from the moment in which it occupies a specific place in the relationship with the patient. This place, in our understanding, is not different from the place occupied by the doctor in the third resistencial hypothesis suggested by Freud. The same observation is also relevant in the second case, in which the fear of dependency -inherent to the treatment contingencies - is indicative of a particular position in which the analyst is being placed by the patient.

In order to be placed theoretically in the context of the Freudian work, it is worth remembering that, at this point, transference was defined as follows: a non-rare phenomenon, justified by the awakening of an affection that, originally linked to a repressed desire in the past, would reappear in the present through the relationship with the doctor, forming like this a false link. Therefore, the occurrence of a transference phenomenonfollows here the path of the formation of the symptom and the means of overcoming it would be to treat it as such.

However, in parallel with the presentation of the concept, we realize that Freud introduced us two ideas that were distinct at first. Let's go back to them: if the first one ratifies the relationship of trust between the analyst and the 
analysant as a possibility to overcome the resistances, the second one tells us that, as a result of this relationship, the fear of becoming dependent can trigger the resistance. Well, it seems that the solution and the cause coincide. Read in this way, the Freudian text allows us to think that the apparent simplicity, with which Freud conceptualizes the transference at first, comprehends by contradiction, the evidence of the extent that the concept will take later.

Going over these examples of Freud, we can identify that the way the author articulates the idea of a "false link" - reducing the doctor to a particular situation in which assignments and affections once directed to another person are displaced to him matches the explanation offered years before about the formation of the hysterical symptom: what is at the origin, both of the notion of false connection, as of the formation of the hysterical symptom, it is a displacement of nervous excitability. To this approximation between the false link and the symptom, we will add now the idea - also previously announced — that, for Freud, a greater deepening in the study of suggestion would help to clarify the mechanism of formation of obsessive ideas since they would both be, in their origin, ruled by the same psychic mechanism, also designed from the displacement of nervous excitement.

It seems reasonable to say that the work of Freud, at that moment, was characterized by the outline of a theory that explains, from a single mechanism, the phenomena that had been thought very frequently in isolation: the symptom (for example, the obsessive ideas), the suggestion (a modality, or even psychic ability) and the transference (which, in dynamic terms, is understandable enough in the context of "fake link"). The triad would have as a first gear the nervous excitability displaced, and "falsely linked", to a part of the body or to the obsessive behavior, both in the figure of a physician or in the ideas and suggestions offered by him. The cause of hysterical symptoms (the mobility of nervous excitability) is also what makes it accessible and transmutable by suggestion - deliberate or not - and inevitably restricts the doctor - hypnotist or not - to a specific position from which he will be able to - or not - play its role. Let us remember what Freud, very early, warned us in Psychotherapy of Hysteria (1895/1990): a treatment reaches good results for the same reasons that it occasionally fails.

In The Interpretation of Dreams, Freud (1900/1990) informs us that the recollection of the first child memories, recognized as such, is not possible. However, during the process of analysis, this access will become feasible by substituting these for "'transferences' and dreams "(Freud, 1900/1990, p. 192).

He adds to this hypothesis the idea that something said by the analyst could touch an "old sensitivity" (ibdem, p. 205), causing the return of the same in 
dreams, covered in disguise. We mention here the analyst's talk working as a daily remaining.

It's important to contextualize that we are following a line of thought organized by the first topical. So we have: an unconscious representation, unable to penetrate the pre-conscious, but withoutfailing to exert some effect on thelatter. Through a connection with a representation that belongs to the pre-conscious, a "transference" of intensity is made in which the pre-conscious representation turns out to cover the unconscious representation and acquiring, as an effect, an "undeserved degree of intensity" (ibdem, p. 513). This intensity transfer to a current representation - to which Freud refers to as substitutive in a child's memory - is notably, on this occasion, synonymous with displacement. Well, if we believe that these displacements, or transferences, are the means to get to the most remote impressions of childhood, it's up to us to ask in what these "transferences" do not consist exactly in the inversion of Bernheim's explanation on suggestion, in which he states that a conscious idea, an "external influence", would operate in the brain of the hypnotized person as if it had arisen spontaneously.

In opposition to what Bernheim had proposed, Freud assumes, from his studies on the oneiric processes, that the analyst's discourse echoes because it works just like the symptom: an idea or the analyst's discourse (or even, an order from the hypnotist) only reaches somewhere because it focuses on something internal, unconscious - that is connected to the idea as if it came from outside. Here, we reserve the right to say that, for the practitioner of psychoanalysis, this description by Freud is easily recognizable in the clinic when, for example, the patient assigns his own meaning to a line from the analyst: "last session you told me to do a particular thing," or "I think you mean that I should do X", and so on. This is a talk (whose meaning is, by nature, always ambiguous) and when focused - using Freud's expression — on an "old sensitivity" is experienced as if it came from outside. As if something was being proposed. It is known that anything the analyst says always gets, for the analysant, its own meaning, more or less clear. And, in the specific case of an analysis process, this gap between speaking and listening is never just something, it doesn't go anywhere. It holds important psychic marks of the analysant. The "suggestion" heard - and that is not always given - is precisely the point at which suggestion materializes in the process in its condition of a psychic mechanism which is common to all.

Weemphasize that one of the main consequences of the thorough investigation that Freud carried out about dreams was the collapse of the barrier which restricted certain psychic mechanisms to hysteria. From this moment on, the dream was explained in the same way that a symptom, and the boundaries between normal and pathological were officially shaken. Something precious lies 
here for our purposes: the same susceptibility to suggestion that allowed the displacement of the hysterical symptom, also allows the displacement mechanism of representations, present in dreams. The excess of nervous excitability loses the connotation of pathology and, from now on, can then be understood as part of the gear. And fundamentally, part of what keeps it moving.

It is obvious that Dora's case (FREUD, 1905a [1901]/1990) became a reference with regard to the scope of the transference and its impact on the progress of the analytical process. Interestingly, all of Freud's elaborations on the transference phenomenon arising from Dora's analysis were the result of his inability to approach it in the course of the treatment. The paradox of this text is in the fact that as it's a case whose supposed failure is attributed to the absence of transference interpretations, what would have made the progress of the treatment impracticable, this article holds numerous ideas that make the notion of transference an event whose complexity surpasses the simple idea of a reprint of the original experience.

Regardingthesource of thetransference, theauthorstatesthat theattachment to certain real details of the person of the doctor is often the way by which the transference may become aware. Its ambiguity with respect to the phenomenon can be perceived when the transference as an indispensable requirement from the theoretical and technical point of view of psychoanalysis is claimed, but that, in clinical practice, this inevitable neurotic production must be crafted as any symptom. It is not a question of establishing a dissonance between theory and practice, but rather to point out how much Freud, already in this early period of his work, recognized in the transference phenomenon a complexity greater than what had been possible to say about it until that moment.

Freud warned us about a portion of what we want to distinguish by proposing that there is a suggestive aspect that will remain via transference and which differs, mainly in terms of the method, from the suggestion used as a therapeutic technique. If in one hand we are advised of the transference risk, on the other the close relationship between transference and the effectiveness of the procedure is highlighted, considering, of course, the differential treatment given by psychoanalysis to this question from the abandonment of the suggestive technique. The emphasis now no longer lies in the person of the doctor and what originates from this figure, but what, from his presence (the doctor's) and accepting, in the place of the analyst, to embody the reprint of the love object, he is able to handle.

There is still one last idea, introduced by Freud in this text, which we believe is of the utmost importance in terms of the scope of transference in the clinical experience, when we think about it in conjunction with suggestion. When questioned about Dora's transference, Freud makes reference to an " $x$ " 
that would relate to the image of Mr. K (ibdem, pp. 112 and 113). He warns about some hypotheses (the issue of money, jealousy of another patient, etc.) and insists on the fact that he couldn't tell which this " $x$ " would be. Well, even if this " $x$ ", as a mnemonic trait, has been reactivated by some personal characteristic, our concern about this specific point relies on the fact that it personifies Freud as a primitive psychic mark of Dora. Even unaware of what this " $x$ " is, it is possible to identify that from this " $x$ " something is inferred to the analyst: knowledge, a feature, a kindness or a harshness in the tone of the voice, for example. Something is inferred to him, and the consequence is a suggestive effect acting behind the analyst.

In his role of analyst, Freud also becomes the owner of " $x$ ", and such feature empowers him, dismisses him and above all will guide the mismatch between the duo analyst/analysant that, as we have already said, is never just something. Suggestion remains because, as a psychic mechanism, it cannot be abandoned. And it is in the presence of the analyst, in his speech, that the means to be updated relies. All the talking, or all the silence, is always suggestive of something that the analyst is unaware of, at least at a first moment.

\section{FINAL CONSIDERATIONS}

The reflections that originate from the central hypothesis of this article (that suggestion remains active in transference despite the analyst) are not presented here as a means to overcome the difficulties inherent to a clinic that has its foundations in the transference phenomenon. On the contrary, our idea is exactly to bring to the discussion the fact that suggestion remains and has specific consequences. And that such consequences - difficult or not - will always be unique. It will always be something particular to each analysant, as this something that, from suggestion, echoes in the analytic relationship is related much more with the uniqueness of the analysant than with what, incidentally, the analyst suggests. We've tried to think of suggestion, from the analysant's point of view (as a psychic process). In other words: suggestion, as a psychic process, looks like a possible name - certainly not the only one - to designate this murky border of transference, where we are, again and again, dragged in the moments in which we occupy the place of the analyst.

In this paper we've decided to strictly highlight that the idea of having suggestion kept away from psychoanalysis cannot be taken without a minimum of reflection. Even if we have limited our considerations to a specific period of the Freudian work, before his writings about the technique, that is, prior to the time when Freud addresses more directly the transference predicaments, we still 
believe that these considerations point to the possibility of devising suggestion as one of the support points of transference- love.

We've emphasized special features that enabled us to relate the suggestive phenomenon both with the symptom and the dream. These same particularities also guide us to the idea that the way Freud systematizes the notion of transference-love presupposes the permanence of a suggestive component which is not extinguished despite the abandonment of its deliberate use as a technique. The investigation of suggestion in its particular relationship with transference- love would take it beyond the limits of the research proposed here. However, we ensure here that the same elements we have carefully selected with the purpose of supporting how inseparable suggestion is from the symptom and the dream, we also value as indications that the abandonment of the suggestive technique by the analyst, cannot be seen as equivalent to the absence of suggestion in the psychoanalytic treatment. Along the lines of this triad (symptom, dream, transference) the permanence of suggestion is a clinical-conceptual requirement that allows us to occupy the place of the analyst, always unique in each analysis.

Recebido/Received: 13/2/2014. Aprovado/Accepted: 19/10/2014.

\section{REFERENCES}

ANDERSSON, O. (2000). Freud precursor de Freud: estudos sobre a pré-história da psicanálise (Luiz Carlos Junqueira Fo, trad.). São Paulo: Casa do Psicólogo.

CHERTOK, L. e STENGERS, I. (1990). O Coração e a Razão, A Hipnose de Lavoisier a Lacan. (Vera Ribeiro, trad.) Rio de Janeiro: Jorge Zahar Editor.

FREUD, S. (1990). Edição Standard Brasileira das Obras Psicológicas Completas de Sigmund Freud (J.Salomão, trad). Rio de Janeiro: Imago.

(1888a) “Histeria" v.l, p. 83-106.

(1888b) “Prefácio à Tradução de De La Suggestion, de Bernheim” v.l, p. 121138.

(1892-1894) “Prefácio e Notas de Rodapé à Tradução de Conferências das Terças-feiras, de Charcot" v.l, p. 195-210.

(1895) "Psicoterapia da Histeria". In BREUER, J. e FREUD, S. (1893-

1895) Estudos sobre a Histeria v.ll, p. 251-294.

(1900) "A Interpretação dos Sonhos" v.IV e V, p. 17-611.

(1905a) "Fragmento da Análise de um Caso de Histeria" v.VII, p. 12115.

(1905b) "Sobre a psicoterapia" v.VII, p. 239-251.

LORENZER, A. (1987). Arqueologia da Psicanálise: Intimidade de Infortúnio Social. (W. de Lyra Chebabi, trad.) Rio de Janeiro: Jorge Zahar Editor. 
Luciana Bacellar Leal Ferreira

lucianabacellar@hotmail.com

Nadja Nara Barbosa Pinheiro

nadjanbp@ufpr.br

Traduzido do português por Doris Dana/translated from portuguese by Doris Dana

dorisdana@uol.com.br 